\title{
Puncta of Neuronal Nitric Oxide Synthase (nNOS) Mediate NMDA Receptor Signaling in the Auditory Midbrain
}

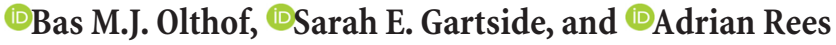 \\ Institute of Neuroscience, Newcastle University, Newcastle upon Tyne NE2 4HH, United Kingdom
}

\begin{abstract}
Nitric oxide (NO) is a neurotransmitter synthesized in the brain by neuronal nitric oxide synthase (nNOS). Using immunohistochemistry and confocal imaging in the inferior colliculus (IC, auditory midbrain) of the guinea pig (Cavia porcellus, male and female), we show that nNOS occurs in two distinct cellular distributions. We confirm that, in the cortices of the IC, a subset of neurons show cytoplasmic labeling for nNOS, whereas in the central nucleus (ICC), such neurons are not present. However, we demonstrate that all neurons in the ICc do in fact express nNOS in the form of discrete puncta found at the cell membrane. Our multi-labeling studies reveal that nNOS puncta form multiprotein complexes with NMDA receptors, soluble guanylyl cyclase (sGC), and PSD95. These complexes are found apposed to glutamatergic terminals, which is indicative of synaptic function. Interestingly, these glutamatergic terminals express both vesicular glutamate transporters 1 and 2 denoting a specific source of brainstem inputs. With in vivo electrophysiological recordings of multiunit activity in the ICc, we found that local application of NMDA enhances sound-driven activity in a concentration-dependent and reversible fashion. This response is abolished by blockade of nNOS or sGC, indicating that the NMDA effect is mediated solely via the NO and cGMP signaling pathway. This discovery of a ubiquitous, but highly localized, expression of nNOS throughout the ICc and demonstration of the dramatic influence of the NMDA activated NO pathway on sound-driven neuronal activity imply a key role for NO signaling in auditory processing.
\end{abstract}

Key words: auditory system; glutamatergic; inferior colliculus; nitric oxide; NMDA receptor; soluble guanylyl cyclase

Significance Statement

We show that neuronal nitric oxide synthase (nNOS), the enzyme that synthesizes nitric oxide (NO), occurs as puncta in apparently all neurons in the central nucleus of the inferior colliculus (ICC) in the auditory midbrain. Punctate nNOS appears at glutamatergic synapses in a complex with glutamate NMDA receptors (NMDA-Rs), soluble guanylyl cyclase (sGC, the NO receptor), and PSD95 (a protein that anchors receptors and enzymes at the postsynaptic density). We show that NMDA-R modulation of sound-driven activity in the ICc is solely mediated by activation of nNOS and sGC. The presence of nNOS throughout this sensory nucleus argues for a major role of $\mathrm{NO}$ in hearing. Furthermore, this punctate form of $\mathrm{nNOS}$ expression may exist and have gone unnoticed in other brain regions.

\section{Introduction}

Nitric oxide (NO) is a signaling molecule in diverse life forms (Feelisch and Martin, 1995; Moroz and Kohn, 2011). In the brain,

\footnotetext{
Received July 27, 2018; revised Nov. 1, 2018; accepted Nov. 26, 2018.

Author contributions: B.M.J.O. wrote the first draft of the paper; B.M.J.O., S.E.G., and A.R. edited the paper; B.M.J.O., S.E.G., and A.R. designed research; B.M.J.O., S.E.G., and A.R. performed research; B.M.J.O. analyzed data; B.M.J.O., S.E.G., and A.R. wrote the paper.

This work was supported by the BBSRC (Grant BB/P003249/1 to A.R. and S.E.G.) and a Flexigrant from Action on Hearing Loss (A.R.). B.M.J.O. was supported in part by a doctoral studentship from Newcastle University. We thank Nick Lesica for generously making available his software for sound stimulation and electrophysiological recording, Vasilis Glykos and Dominika Lyzwa for writing some of the analysis code, and John Garthwaite for advice on drugs for modulating the nNOS pathway. Gavin Clowry, Evelyne Sernagor and Andrew Trevelyan kindly provided comments on an early version of the manuscript.

The authors declare no competing financial interests.

Correspondence should be addressed to Adrian Rees at adrian.rees@ncl.ac.uk.

https://doi.org/10.1523/JNEUROSCI.1918-18.2018

Copyright $\odot 2019$ the authors $\quad 0270-6474 / 19 / 390876-12 \$ 15.00 / 0$
}

NO is produced through the action of the calcium/calmodulindependent enzyme neuronal nitric oxide synthase (nNOS) and is involved in intracellular and intercellular signaling in neurons and glia (Garthwaite, 2008, 2016). NO can act within the cell in which it is produced or it may diffuse across the cell membrane to act in presynaptic terminals or by volume transmission at more distant sites (O’Dell et al., 1991; Steinert et al., 2008; Hardingham et al., 2013; Bellefontaine et al., 2014; Garthwaite, 2016).

Several studies have shown a functional interaction between glutamate NMDA receptor (NMDA-R) activation, nNOS, and soluble guanylyl cyclase (sGC), the enzyme catalyzing the production of cGMP and the main downstream receptor of NO. $\mathrm{Ca}^{2+}$ entering through the NMDA-R (Garthwaite et al., 1988) activates nNOS and the NO produced activates sGC (Arnold et al., 1977), leading to increased levels of cGMP. 
The functional coupling of the NMDA-R, nNOS, and sGC suggests they should be in close proximity to each other, and located at glutamatergic synapses. Studies have shown that nNOS binds to a scaffolding protein, postsynaptic density protein 95 (PSD95) (Brenman et al., 1996). This protein also anchors the NMDA-R at the postsynaptic membrane (Valtschanoff and Weinberg, 2001; Burette et al., 2002). Furthermore, an isoform of soluble guanylyl cyclase has been shown to bind to PSD95 in brain homogenates (Russwurm et al., 2001). Thus far, however, the four proteins (PSD95, the NMDA-R, nNOS, and sSG) have not been shown to exist as a single complex in native tissue.

Most studies exploring NO signaling in the brain have been in hippocampus, cerebellum, and cortex (Garthwaite et al., 1988; Shibuki and Okada, 1991; Hardingham and Fox, 2006). However, nNOS occurs in many other brain regions, including those associated with sensory processing. Despite the presence of nNOS in sensory systems, with a few exceptions (e.g. Cudeiro et al., 1994; Steinert et al., 2008, 2011; Lima et al., 2014; Yassin et al., 2014; Kopp-Scheinpflug et al., 2015), relatively little attention has been given to the role of NO in such regions. One sensory structure expressing particularly high levels of nNOS is the inferior colliculus (IC) (Endoh et al., 1994). This principal midbrain center of the auditory pathway processes virtually all ascending auditory information, which it integrates with descending projections from the forebrain and nonauditory inputs (Oliver and Cant, 2018).

The IC consists of three subdivisions. The dorsal and lateral cortices (ICD and ICL) (Faye-Lund and Osen, 1985; Oliver, 2005) contain neurons that express nNOS densely throughout their somata and dendrites (Herbert et al., 1991; Druga and Syka, 1993; Coote and Rees, 2008). Injection of nNOS inhibitors into ICD influences sound evoked potentials in the cerebral cortex (Iannone et al., 1996), suggesting that NO signaling in these neurons has a functional role in sound processing. The third subdivision is the tonotopically organized central nucleus (ICC). Its primary inputs are ascending auditory projections from the brainstem and its output is the main source of input to the higher auditory system. nNOS-filled neurons are absent from the greater part of the ICC and occur only at its border with ICD, suggesting that $\mathrm{NO}$ signaling is not a feature of this nucleus (Coote and Rees, 2008).

In contrast to earlier studies, we report here that all neurons in the ICC apparently do contain nNOS, but that this occurs in a previously undescribed punctate form. We demonstrate that nNOS puncta coexist with NMDA-Rs, sGC, and PSD95, forming multiprotein signaling complexes, and these occur in apposition to glutamatergic terminals, indicating their synaptic location. We highlight the functional importance of these synapses by showing that NMDA modulates sound-driven activity in the ICC in vivo and that this response is mediated via nNOS and sGC.

\section{Materials and Methods}

\section{Animals}

Experiments were performed in accordance with the terms and conditions of a license (PPL 60/3934) issued by the UK Home Office under the Animals (Scientific Procedures) Act of 1986 and with the approval of the Local Ethical Review committee of Newcastle University. Male and female adult pigmented guinea pigs (Cavia porcellus) were bred in-house and kept in spacious housing conditions with food and water available ad libitum. Animals were used for experiments between the ages of 40 and $200 \mathrm{~d}$.

\section{Immunohistochemistry}

Tissue collection and preparation. Animals were deeply anesthetized with pentobarbital and transcardially perfused with either heparinized $0.1 \mathrm{M}$
PBS followed by $4 \%$ PFA in PBS or with 4\% PFA only. The brains were postfixed overnight in $4 \%$ PFA, cryoprotected in 30\% sucrose, and stored at $-80^{\circ} \mathrm{C}$ until they were processed. Coronal sections $(40 \mu \mathrm{m})$ through the IC were cut on a freezing microtome and collected into PBS. Sections not immediately required were stored in an antifreeze solution $(30 \%$ ethylene glycol, $30 \%$ sucrose, $1 \%$ polyvinyl pyrrolidone-40 in PBS) (Watson et al., 1986) at $-20^{\circ} \mathrm{C}$.

Immunohistochemistry. Sections were washed in PBS $(3 \times 10 \mathrm{~min})$, incubated in $5 \% \mathrm{NaBH}_{4}$ (20 min) (for antigen retrieval), and washed again in PBS $(3 \times 10 \mathrm{~min})$. Sections were then incubated (overnight at $4^{\circ} \mathrm{C}$ ) with primary antibodies diluted in a "block buffer" comprising $0.1 \%$ porcine gelatin $(\mathrm{BDH})$ and $1 \%$ bovine serum albumin (SigmaAldrich) in $50 \mathrm{~mm}$ glycine (Fisher Scientific) in PBS (with or without 0.05-0.1\% Triton X-100; Sigma-Aldrich). In some cases, sections were preincubated in block buffer $(1-2 \mathrm{~h})$ before addition of the primary antibodies. The following nNOS antibodies were used: rabbit anti-nNOS (1:2000, Sigma-Aldrich catalog \#N7280, RRID:AB_260796); mouse anti-nNOS (1:250-1:500, Sigma-Aldrich catalog \#N2280, RRID: AB_260754); sheep anti-nNOS (1:500, Millipore catalog \#AB1529, RRID:AB_90743). We established that all three antibodies resulted in near identical labeling. We also used goat anti-PSD95 (1:1000, Abcam catalog \#ab12093, RRID:AB_298846); rabbit anti-sGC $\alpha 2 \beta 1$ subunit (1: 1000, Abcam catalog \#ab42108, RRID:AB_732741); mouse anti-GluN1 (NMDA-R subunit) (1:500, Millipore catalog \#MAB363, RRID: AB_94946); goat anti-VGluT1 (1: 500, Synaptic Systems catalog \#135 307, RRID:AB_2619821); rabbit anti-VGluT2 (1:1000, Synaptic Systems catalog \#135 403, RRID:AB_887883); rabbit anti-VGAT (1:1000, Synaptic Systems catalog \#131 003, RRID:AB_887869); rabbit antiNeurochrom (PAN) (which labels somatic, nuclear, dendritic, and axonal neuronal proteins) (1:2000-4000, Millipore catalog \#ABN2300, RRID:AB_10953966); rabbit anti-GABA (1:500-1:1000, Sigma-Aldrich catalog \#A2052, RRID:AB_477652); mouse anti-NeuN (1:1000, Merck catalog \#MAB377, RRID:RRID:AB_2298772).

After overnight incubation, sections were washed $(3 \times 10 \mathrm{~min}$ PBS $)$ and incubated for $2 \mathrm{~h}$ with secondary antibodies diluted in 5\% normal goat serum (Vector Laboratories) in PBS. The following secondary antibodies were used (all at 1:500 dilution): Alexa Fluor 568 goat anti-rabbit (Thermo Fisher Scientific catalog \#A-11036, RRID:AB_10563566); Alexa Fluor 488 goat anti-mouse (Thermo Fisher Scientific catalog \#A-11029, RRID:AB_2534088); Alexa Fluor 488 chicken anti-rabbit (Thermo Fisher Scientific catalog \#A-21441, RRID:AB_2535859); Alexa Fluor 488 donkey anti-sheep (Thermo Fisher Scientific catalog \#A-11015, RRID: AB_2534082); CY5 donkey anti-goat (Abcam catalog \#ab97117, RRID: AB_10679586); AMCA donkey anti-mouse (Jackson ImmunoResearch Laboratories catalog \#715-155-151, RRID:AB_2340807). Sections were washed in PBS $(1 \times 10 \mathrm{~min})$, incubated with the nuclear stain $4^{\prime}$, 6-diamidino-2-phenylindole (DAPI, Invitrogen) (10 min, 1-2 nM in PBS), washed in PBS $(1 \times 10 \mathrm{~min})$, and finally rinsed in distilled water. Sections were mounted on glass slides, air dried, and coverslipped with Fluoroshield (Sigma-Aldrich). Slides were stored in the dark at $4^{\circ} \mathrm{C}$.

For single-labeling experiments and double labeling of nNOS and NeuN, nNOS was labeled using rabbit anti-nNOS visualized with Alexa Fluor 488 or 568 goat anti-rabbit secondary. For double labeling of nNOS and PAN, nNOS and GABA, nNOS and VGAT, as well as triple labeling of nNOS with VGLUT1 and VGLUT2, nNOS was labeled with mouse anti-nNOS visualized with Alex Fluor 488 goat anti-mouse secondary. For the quadruple labeling of nNOS, with PSD95, GluN1 (hereafter called NMDA-R), and sGC, nNOS was labeled with sheep anti-nNOS visualized with Alexa Fluor 488 donkey anti-sheep.

For each antigen and combination, three sections collected along the rostral caudal axis of the IC from at least four different animals were labeled. Sections processed and incubated with secondary antibodies in the absence of primary antibody were included as controls.

Image acquisition and analysis. To examine the distribution of labeling throughout the IC, low-power $(20 \times)$ mosaics were acquired using a Zeiss AxioImager with ZenPro software. Tiles were stitched during image acquisition and images were deconvolved using Huygens Essential (SVI). To examine the subcellular distribution of antibody labeling and the proximity of different labels, $Z$-stacks ( $Z$ step $0.1-0.3 \mu \mathrm{m}$ ) were acquired 
using a $63 \times$ oil-immersion objective on a Nikon A1+ point scanning confocal microscope with Nikon Elements software. The microscope was equipped with four solid state lasers at $405,488,561$, and $647 \mathrm{~nm}$. Images were acquired at resolution of 1024 pixels in the $X-Y$ dimension. $Z$ dimensions were variable. Pixel dimensions were kept at $60 \mathrm{~nm}$ for $X Y$ with bit depth 12, look-up tables were kept linear and covered the full range of the data collected. $Z$-stacks for all of the required antibody combinations were acquired from three sections collected along the rostral caudal axis of the IC from at least four different animals. In every section, two $Z$-stacks were acquired from each region. $Z$-stacks were deconvolved using Huygens Essential (SVI) using a theoretical point spread function, automated background estimation, deconvolved with the classic maximum likelihood estimation algorithm, quality threshold 0.05 , with a maximum number of iterations set at 100 . The deconvolved $Z$-stacks were subsequently analyzed using Imaris version 9.0 software (Bitplane). To examine the proximity of the nNOS puncta to puncta labeled for PSD-95, sGC, and NMDA-R, all labeled puncta were first defined using the "spot" function. Around each nNOS spot, we created a sphere of interest with a radius of $0.2 \mu \mathrm{m}$. This value was chosen on the basis of the average length of a postsynaptic density being $0.2-0.8 \mu \mathrm{m}$ (Sheng and Hoogenraad, 2007). Using the "colocalize-spot" function, we then identified the population of nNOS spots that were in close proximity to at least one PSD-95 spot (i.e., within the sphere). Next, we determined how many of these nNOS- and PSD-95-containing spheres also contained one or more NMDA-R spots. Finally, we determined how many of the nNOS/NMDA-R/PSD-95-containing spheres also contained one or more sGC spots. This allowed us to calculate the proportion of nNOS puncta that were in close proximity to PSD-95 and NMDA-R and sGC puncta.

To examine the proximity of nNOS puncta to specific subtypes of glutamatergic terminals, we first rendered VGluT1 + VGluT2 labeling using the spot function. Next, to define populations of terminals labeled for VGluT1 only, VGluT2 only, and for both VGluT1 and VGluT2, we used colocalize-spots within a sphere of $0.1 \mu \mathrm{m}$. Finally, to determine whether individual nNOS puncta were in close proximity to the three populations of glutamatergic terminals, we used the colocalize-spot function and a sphere of $0.6 \mu \mathrm{m}$ radius around the nNOS punctum as our definition of close proximity.

\section{In vivo electrophysiological recording}

Surgical preparation. Animals were anesthetized with a combination of urethane (1 mg/kg, i.p.; Sigma-Aldrich), fentanyl $(0.3 \mathrm{mg} / \mathrm{kg}$, i.p.; Hameln) and midazolam (5 mg/kg, i.m.; Hameln). Following induction, animals received supplementary doses of fentanyl as required to prevent a withdrawal response to a hind toe pinch. Atropine $(0.05 \mathrm{mg} / \mathrm{kg}$, s.c. $)$ was also administered to suppress bronchial secretions. A tracheotomy was performed and the animal was allowed to respire freely in an atmosphere enriched with medical oxygen or artificially respired as required with oxygen using a modified small animal respirator (Harvard Apparatus). The animal was transferred to a sound-attenuated room and fixed in a modified stereotaxic frame (Kopf Instruments) equipped with ear bars with Perspex specula positioned to allow an unobstructed view of the tympanic membrane. The animal's body temperature was monitored with a rectal probe and maintained at $38^{\circ} \mathrm{C}$ with a thermostatically controlled electric heating pad (Harvard Apparatus).

A craniotomy was performed over either the left or right IC and the cerebral cortex overlying the IC was aspirated. Concentric microdialysis probes (3 mm dialyzing window; AN69 Hospal membrane) were manufactured in-house by threading 2 sections of silica fused fiber (ID $110 \mu \mathrm{m}$ /OD $170 \mu \mathrm{m}$, SGE Analytical Science) through a Y-shaped body constructed of tubular stainless steel (Goodfellow AISI 304, Fe/Cr18/Ni10; diameter $0.5 \mathrm{~mm}$; wall thickness $0.06 \mathrm{~mm}$ ) glued with Araldite. A probe was implanted under visual control into the IC directed mediolaterally at $10^{\circ}$ from the vertical to a depth of $\sim 4 \mathrm{~mm}$ below the surface of the IC. The microdialysis probe was constantly perfused $(2 \mu \mathrm{l} / \mathrm{min})$ with artificial CSF (aCSF) composed of the following (in $\mathrm{mm}$ ): $\mathrm{NaCl} 140, \mathrm{KCl} 3$, $\mathrm{Na}_{2} \mathrm{HPO}_{4}$ 0.707, $\mathrm{NaHPO}_{4}$ 0.272, $\mathrm{MgCl}_{2}$ 1, D-glucose 10, and $\mathrm{CaCl}_{2} 2.4$. Microdialysis provided an effective means of delivering drugs directly into the brain. Because drugs diffuse across the membrane, no mechanical perturbation occurs as the drug is applied (Orton and Rees, 2014).

A recording probe with 32 channels arranged linearly over $3.2 \mathrm{~mm}$ (100 $\mu \mathrm{m}$ spacing; Neuronexus A1x65-10 mm-100-177-A32 50) was implanted vertically in the IC immediately rostral to the microdialysis probe. The depth of the electrode was adjusted to capture responses to the widest range of sound frequencies based on frequency response areas (Palmer et al., 2013) derived from the recorded activity.

Sound stimuli and recording. The electrode was connected to a head stage (NN32AC; Tucker Davis Technologies) connected to a 32-channel preamplifier (PZ2-32; Tucker Davis Technologies) connected by an optical interface to a BioAmp (RZ2; Tucker Davis Technologies). Electrophysiological data were sampled at $24.414 \mathrm{kHz}$. Multiunit activity was recorded from all 32 channels in response to pure tones $(75 \mathrm{~ms}$ duration, $10 \mathrm{~ms}$ rise/fall time, total sweep duration $150 \mathrm{~ms}$ ) at 256, 512, 1024, 2048, and $4096 \mathrm{~Hz}$ presented at nominal levels of 50 and $70 \mathrm{~dB}$ sound pressure level generated by a Multi I/O Processor (RZ6; Tucker Davis Technologies) at a sampling rate of $97.656 \mathrm{kHz}$. Tones were delivered to the animal with Sony MDR 464 earphones housed in alloy enclosures coupled to damped probe tubes that fitted into the Perspex specula (Rees, 1990). Peristimulus time histograms (PSTHs) were generated from multiunit activity collected over 150 stimulus repeats for each frequency and level. MATLAB scripts were used to control stimulus presentation and data recording, and to store recorded spike data for offline analysis.

Drug application. Following a baseline period of recording (minimum $1 \mathrm{~h}$, beginning at least $1 \mathrm{~h}$ after implantation of the electrode) during which aCSF was perfused through the dialysis probe, the perfusate was switched to aCSF containing one or more drugs [NMDA 30, 100, $300 \mu \mathrm{M}$, Sigma-Aldrich; $\mathrm{N}^{\mathrm{G}}$-methyl-L-arginine (L-MeArg) also known as $\mathrm{N}^{\mathrm{G}}$-monomethyl-L-arginine (L-NMMA), $1 \mathrm{~mm}$, Sigma-Aldrich; or $1 \mathrm{H}$ [1,2,4] oxadiazolo[4,3-a]quinoxalin-1-one (ODQ), $500 \mu \mathrm{M}$, SigmaAldrich]. To obtain a concentration-response measure for NMDA, increasing concentrations of NMDA were perfused for $\sim 40$ min interspersed with intervals of $\sim 40 \mathrm{~min}$ aCSF (washout). For the L-MeArg and ODQ experiments, NMDA $(100 \mu \mathrm{M})$ was perfused for $40 \mathrm{~min}$ followed by $40 \mathrm{~min}$ aCSF (washout), then 20 min of L-MeArg or ODQ, then 40 min of NMDA plus L-MeArg or ODQ, 40 min of aCSF, 40 min of NMDA, and finally $40 \mathrm{~min}$ of aCSF. PSTH blocks were generated throughout the periods of drug/aCSF perfusion.

We based our perfusion times on the temporal and spatial analysis of the effects of lidocaine infusion by microdialysis reported by Boehnke and Rasmusson (2001). We present data from recordings made $20 \mathrm{~min}$ after the onset of drug infusion, the time at which drug tissue concentration achieved a maximal and steady level in Boehnke and Rasmussen's (2001) analysis. Washout data presented are from recordings made 40 min after return to perfusion of aCSF.

Analysis. Offline electrophysiological recordings from all channels were band-pass filtered with cutoff of 300 and $3000 \mathrm{~Hz}$ and thresholded at 2.5 times the SD of the spontaneous activity in the baseline block collected during sweeps in which the stimulus was maximally attenuated by $120 \mathrm{~dB}$. For all subsequent blocks, "activity" was defined as spikes exceeding this threshold. Data were analyzed from electrode sites best representing each of the five frequencies: 256, 512, 1024, 2048, and 4096 $\mathrm{Hz}$. For each frequency and level, PSTHs with a bin width of $1 \mathrm{~ms}$ and a duration of $150 \mathrm{~ms}$ were constructed from 150 sweeps of thresholded data. The beginning of the sound-driven response was identified and spikes in a window extending $80 \mathrm{~ms}$ from that time were summed to give the driven response. Driven and spontaneous response rates measured during the different drug/washout conditions were exported to IBM SPSS Statistics V23 for statistical analysis.

\section{Experimental design and statistical analysis}

Immunohistochemistry data cited are descriptive statistics (mean \pm $\operatorname{SEM}(n)$ where $n=$ number of $Z$-stacks). Measures were made on two $Z$-stacks per ICc from each of three sections taken from each of four animals ( $24 Z$-stacks in total). $Z$-stacks were obtained at $63 \times$ magnification with digital zoom and each one contained between 9 and 15 neuronal somata. 

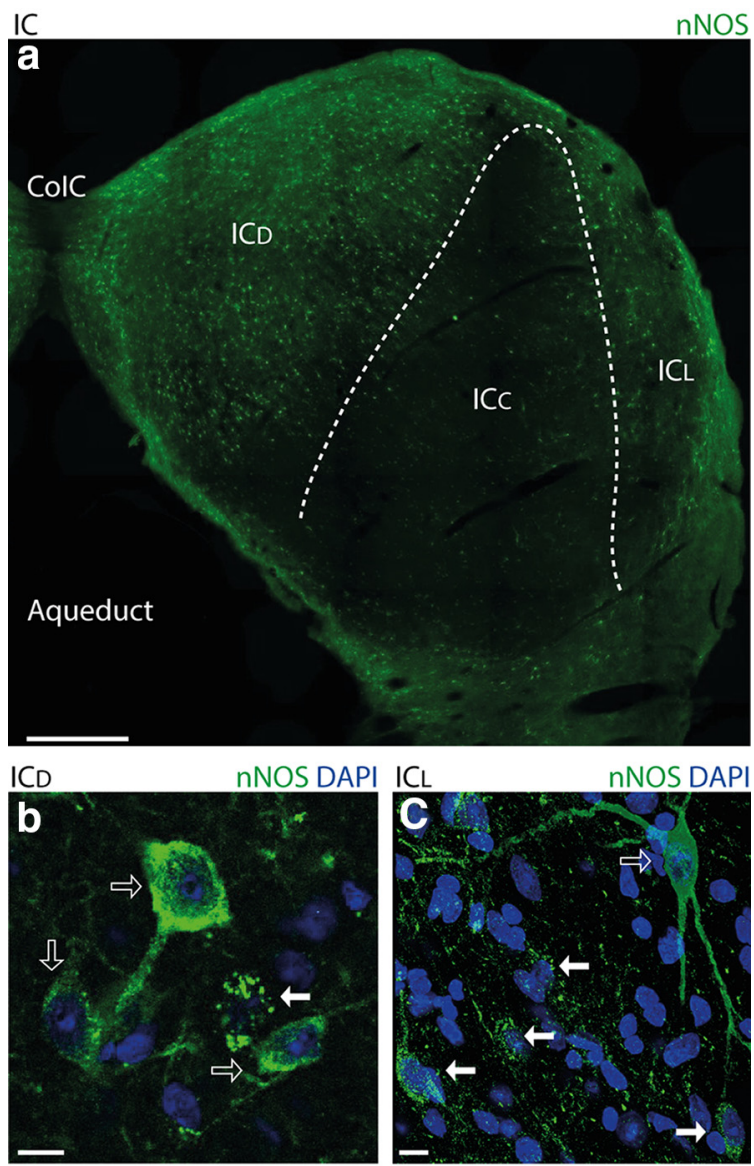

nNOS DAPI
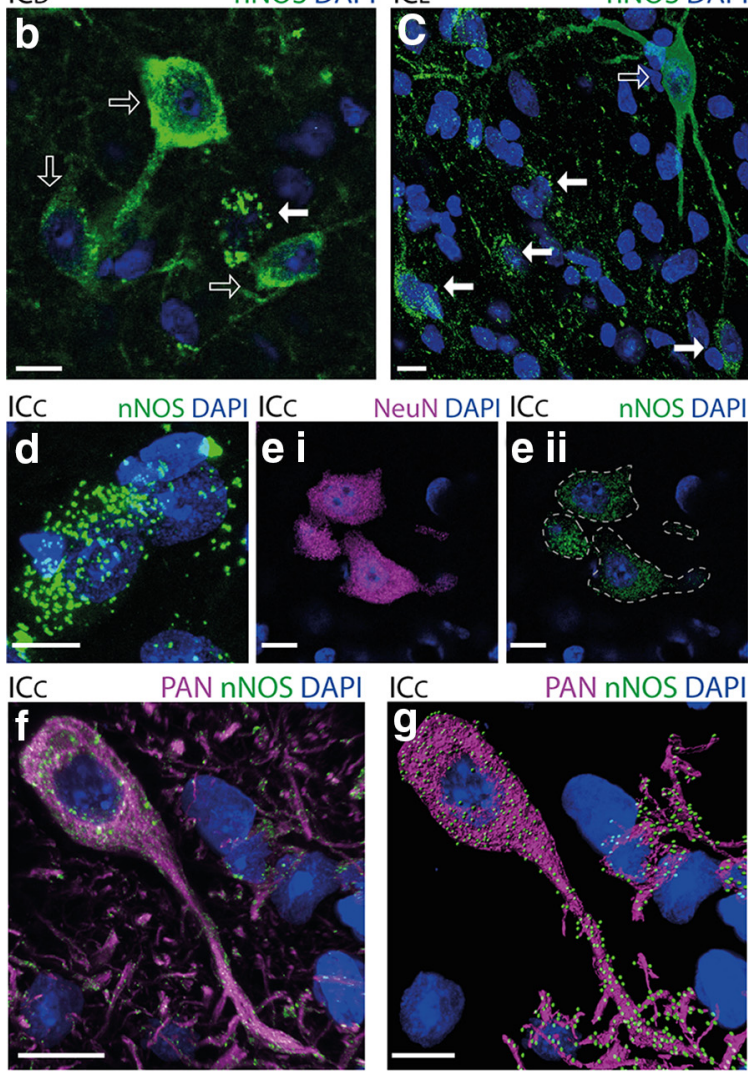

ICD

GABA nNOS DAPI ICC
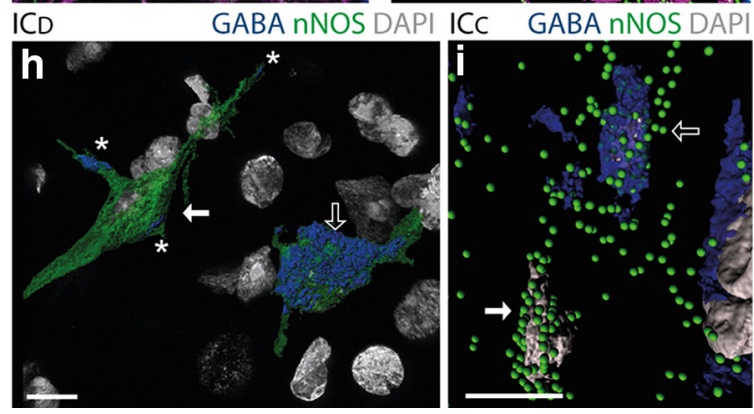

Figure 1. nNOS expression occurs in all subdivisions of the IC. $\boldsymbol{a}$, Mosaic image of a $40 \mu \mathrm{m}$ coronal IC section labeled for nNOS (green). $\mathrm{nNOS}$ can be seen densely expressed in the ICD and ICL, whereas expression is apparently absent from most of the ICC. $\boldsymbol{b}$, In the ICD, there are many
Electrophysiological studies were designed to allow within-subjects comparisons. Multichannel probes allowed us to gather data from multiple sites in the ICC of individual animals that corresponded to the best response to each of five frequencies. Responses were determined for each frequency under different conditions (increasing concentrations of NMDA and washout or NMDA with or without L-MeArg or ODQ) in groups of $n=3$ or $n=4$ animals. After testing for sphericity (Mauchly), the data were analyzed using a two-way repeated-measures ANOVA with "frequency" and "drug condition" as within-subject factors. Significant main effects were further analyzed using planned post hoc paired-sample $t$ tests (two tailed) on relevant comparisons. These were corrected for multiple comparisons using the Sidak method.

\section{Results}

Two different patterns of nNOS distribution in the IC

To elucidate the functional properties of NO in the IC, we first examined the regional, cellular, and subcellular distribution of its synthetic enzyme, nNOS, in the guinea pig IC using fluorescence immunohistochemistry. At low magnification, abundant expression of nNOS is apparent in the ICD and ICL, but little or no expression is visible in the ICC (Fig. 1a). Many neurons are visible in the ICD and ICL, which have nNOS distributed diffusely throughout the cytoplasm of their somata and dendrites (Fig. $1 b, c)$. However, at high magnification, scattered among these cytoplasmically labeled neurons (Fig. 1c), we observed bright spots of nNOS labeling (Fig. 1c) that we dubbed "nNOS puncta." The discovery of nNOS puncta prompted us to look more closely at the ICC, a region devoid of cytoplasmically labeled nNOS neurons. Here, again under high magnification, many nNOS puncta $(0.4-0.8 \mu \mathrm{m}$ in diameter) were visible clustered around nuclei apparently outlining cell somata (Fig. 1d). Double labeling for nNOS and the neuronal marker NeuN showed that these cells were neurons and also revealed, surprisingly, that the somata of apparently all neurons in the ICC contain nNOS puncta (Fig. 1ei,eii). Double labeling for nNOS and Neurochrom (a panneuronal antibody mixture labeling somatic, nuclear, dendritic, and axonal proteins) indicated that all nNOS puncta are neuronal and that they occur within other neuronal elements as well as somata (Fig. 1f,g).

To determine the neurotransmitter phenotype of neurons containing nNOS puncta, we performed double labeling with antibodies for nNOS and GABA. In the ICD and ICL (Fig. $1 h$ ), as well as

\footnotetext{
$\leftarrow$

neurons with nNOS distributed diffusely throughout their cytoplasm (open arrows). However, puncta of nNOS (closed arrow) surrounding a DAPI-stained nucleus (blue) can also be observed in this region. $c$, In the ICL, large neurons with extensive dendrites completely filled with nNOS are visible (open arrow). Again, however, puncta of nNOS (closed arrow) surrounding a DAPIstained nucleus (blue) can also be observed in this region d, Although the ICc appears devoid of nNOS at low magnification, at higher-magnification puncta of nNOS surrounding DAPI stained nuclei are revealed. $\boldsymbol{e}$, In the ICc, virtually all neurons visualized by NeuN (ei, magenta) show signs of punctate nNOS expression (eii, green). In eii, dotted lines outline cell somata visualized by NeuN labeling.f, Dual immunohistochemistry for nNOS (green) and a pan neuronal antibody mixture (PAN, magenta) showing that nNOS-labeled puncta are present on the membrane of both somata and dendrites. $\boldsymbol{g}$, Rendering in Imaris showing clearly how nNOS puncta (green spots) are localized on neuronal elements (magenta surfaces). $\boldsymbol{h}$, In the ICD, dual immunohistochemistry for nNOS (green) and GABA (blue) rendered in Imaris shows that some nNOS-filled cells contain GABA (open arrow), whereas others are GABA-negative (closed arrow) and are presumed to be glutamatergic. Note that the GABA labeling (asterisks) on the glutamate neuron shown here (closed arrow) is restricted to the surface and therefore considered to be terminals. In contrast, the GABAergic neuron (open arrow) shows GABA labeling throughout its cytoplasm. $\boldsymbol{i}$, In the ICC, Imaris rendering shows that some cells in the ICC with nNOS puncta (green) also contain GABA (blue, open arrow), whereas others do not (closed arrow) and are presumed to be glutamatergic. ColC, Intercollicullar commissure; Aqueduct, the aqueduct of Sylvius. Scale bars, $10 \mu \mathrm{m}$ (except in $\boldsymbol{a}$, where it is $500 \mu \mathrm{m}$ ).
} 

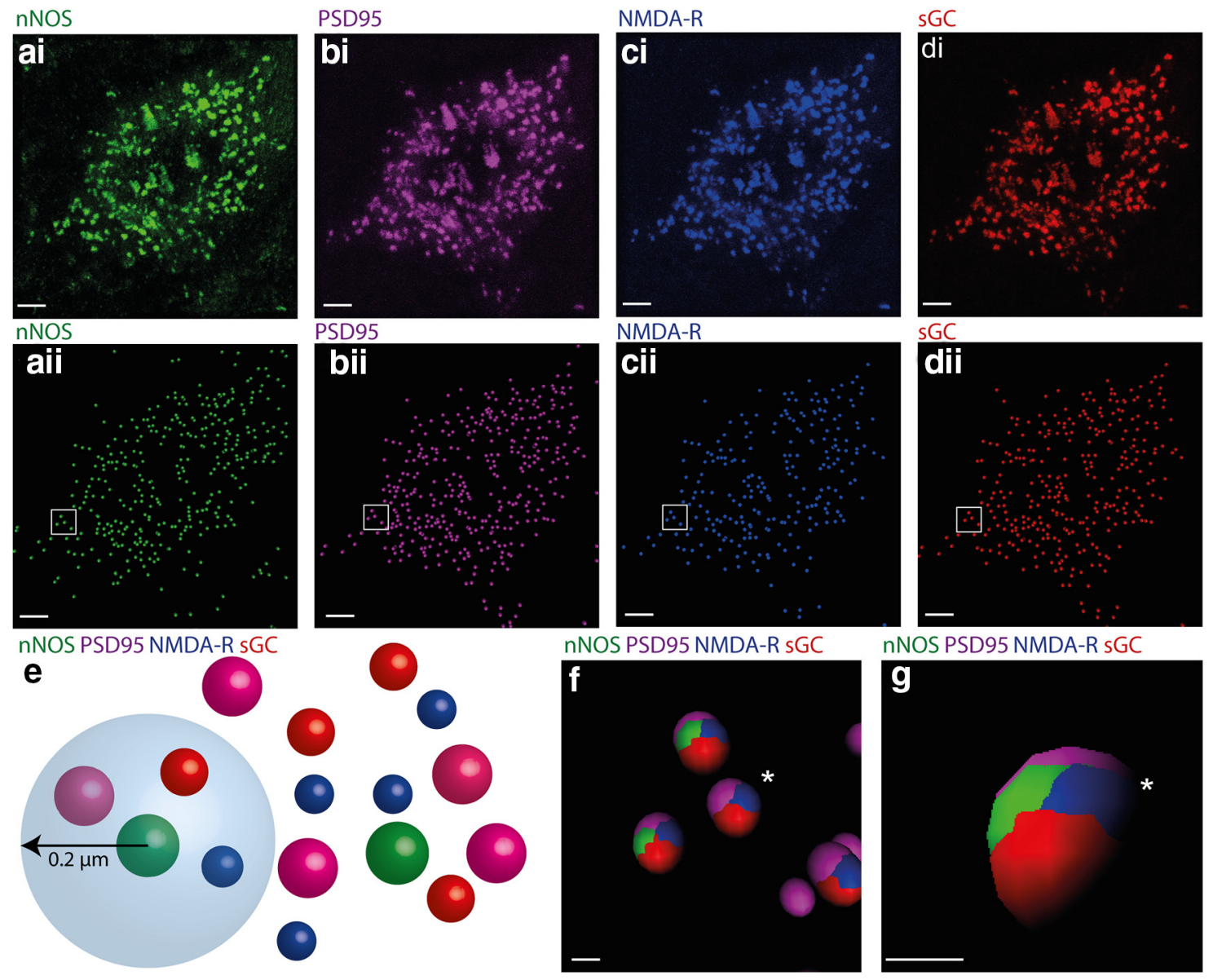

nNOS PSD95 NMDA-R sGC

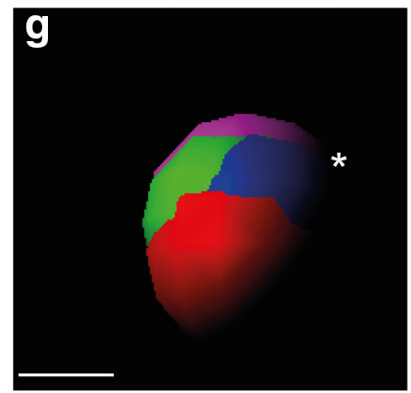

Figure 2. nNOS puncta in the IC are in close proximity to puncta labeled for PSD95, NMDA-R, and sGC. ai, Cell soma in the ICc showing nNOS puncta (green). The same cell also contains PSD-95 (bi, magenta), NMDA-R (ci, blue), and sGC (di, red). In aii, bii, cii, and dii, labeled puncta in the raw images $\boldsymbol{a i}$-di have been rendered to spots in Imaris. $\boldsymbol{e}$, lllustration showing how we determined whether individual nNOS puncta were in close proximity to puncta labeled for PSD95, NMDA-R, and sGC. A sphere of $0.2 \mu \mathrm{m}$ radius was centered on each nNOS spot and the occurrence of PSD95, NMDA-R, and sGC spots within this sphere was determined. $f$, Ellipsoids (shown for the box in aii-dii) are colored to show the occurrence of the four proteins within the $0.2 \mu \mathrm{m}$ sphere of interest. Virtually all nNOS spots are in close proximity to spots representing PSD-95, NMDA, and sGC. Note that even where only three colors are seen in this $2 \mathrm{D}$ view (cluster marked by *), when the vantage point is changed $(\boldsymbol{g})$, the fourth color can be seen. Scale bars: $\boldsymbol{a}-\boldsymbol{d}, 10 \mu \mathrm{m} ; \boldsymbol{f}, \boldsymbol{g}, 1 \mu \mathrm{m}$.

in the ICC (Fig. 1i), nNOS expression was observed in both GABApositive (Fig. 1h, $i$, open arrows) and GABA-negative neurons. Because virtually all IC neurons are either glutamatergic or GABAergic (Oliver et al., 1994; Merchán et al., 2005), GABA negative neurons are likely to be glutamatergic (Fig. $1 h, i$, filled arrows).

\section{Punctate nNOS is structurally associated with PSD95, the} NMDA-R, and sGC

In the ICC, we observed nNOS puncta at the neuronal membrane. We reasoned that, if they occur in close proximity to NMDA-Rs and sGC, then they could be involved in NMDA-R neurotransmission. We used high-resolution confocal microscopy and image analysis to visualize quadruple immunofluorescence labeling for nNOS, GluN1 (the obligatory subunit of the NMDA-R), and sGC $\alpha_{2} \beta_{1}$ (hereafter sGC), together with PSD95.

Dense, punctate labeling for PSD95 and NMDA-R was found throughout the ICC. Both punctate and diffuse sGC labeling could also be seen within ICc neurons. High-resolution confocal imaging revealed considerable overlap between the subcellular distribution of the nNOS puncta (Fig. 2ai) and labeling for PSD95 (Fig. 2bi), NMDA-R (Fig. 2ci), and sGC (Fig. 2di). To verify the association between these proteins, their puncta were first rendered to spots using Imaris (Fig. 2aii-dii). We then created a sphere of interest $0.2 \mu \mathrm{m}$ in diameter around the center of each nNOS spot and determined whether spots for PSD95, NMDA-R, and sGC occurred within this sphere (Fig. 2e).

Almost all $(92 \pm 4 \%)$ of the spheres around nNOS puncta contained labeling for PSD95 and NMDA-R and sGC, demonstrating that nNOS puncta almost always occur in proximity to NMDA, sGC, and PSD95 (Fig. 2f,g). Interestingly, this analysis revealed a highly consistent order of labeling within the spheres with nNOS and NMDA-R sandwiched between sGC and PSD95 (Fig. 2f,g). This consistency suggests that the four protein elements occur in a fixed structural arrangement.

To estimate the extent to which NMDA neurotransmission in the ICc is mediated by NO, we also determined the proportion of the total NMDA-R spots in the ICC that are associated with nNOS. On neuronal somata in the ICC, $84 \%$ ( $\pm 5 \%)$ of the NMDA-R spots were associated with nNOS spots. However, at nonsomatic sites, presumably dendrites, only $19 \%( \pm 6 \%)$ of NMDA-R spots were associated with nNOS spots.

\section{nNOS puncta are postsynaptic to glutamatergic terminals}

The association of nNOS puncta with NMDA-R suggests that they occur at glutamatergic synapses. To test this prediction, we determined whether nNOS puncta are associated with labeling for the VGluT1 + VGluT2 subtypes of the presynaptic terminal vesicular glutamate transporter. To exclude the association of 


\section{DAPIVGIUT1 VGIUT2 VGIUT1\&2}
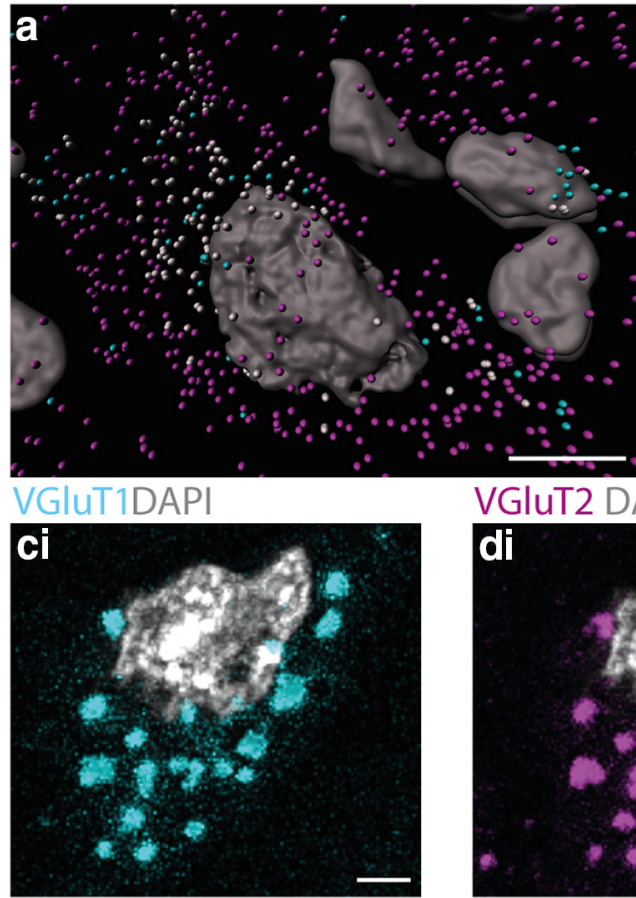

VGIUT1DAPI

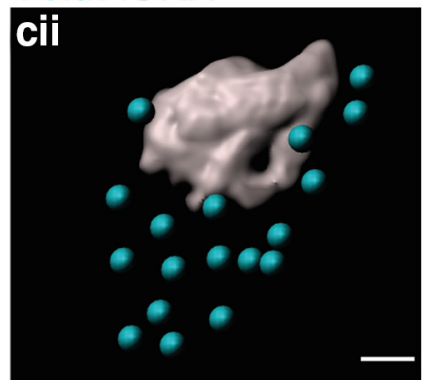

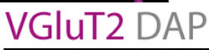

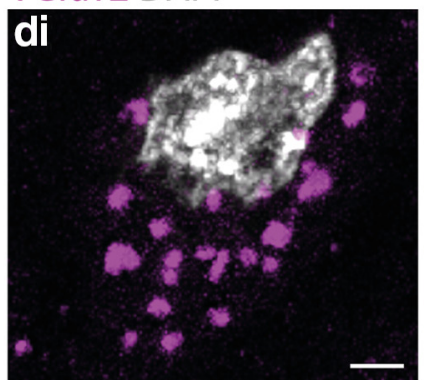

VGIUT2 DAPI

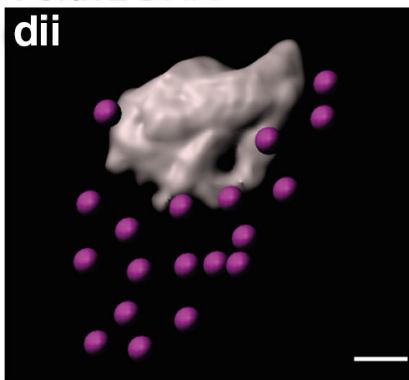

VGAT nNOS DAPI

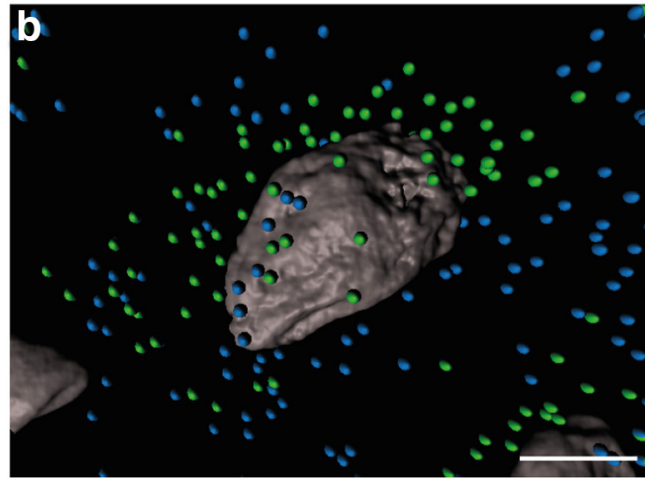

nNOS DAPI
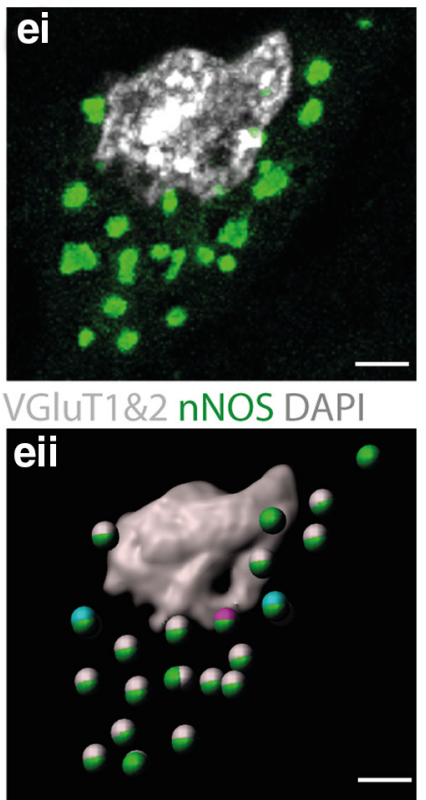

Figure 3. nNOS puncta in the IC are innervated by glutamatergic terminals that predominantly contain both VGluT1 and VGlutT2. $a$, Imaris rendering of a neuron containing nNOS puncta (omitted for clarity) in the ICc showing the distribution of terminals containing VGluT1 only (cyan), VGluT2 only (magenta), and VGluT1 + VGluT2 (white). Note that this neuron receives a substantial number of terminals labeling for VGluT2 only (magenta) and a smaller number of terminals labeling for VGluT1 + VGluT2 (white), whereas terminals labeling for VGluT1 only (cyan) are infrequent. $\boldsymbol{b}$, Imaris rendering of a cell in the ICc with GABAergic/glycinergic terminals containing VGAT (blue) and nNOS puncta (green). Note that this cell receives GABAergic/glycinergic terminals, but there is no correspondence between these and the nNOS puncta. ci-ei, Slice from a Z-stack showing a neuron from the ICc. Labeling for VGluT1 (ci, cyan), VGluT2 (di, magenta), and nNOS (ei, green). cii-eii, Z-stacks containing the images in ci-ei were rendered to spots in Imaris representing glutamatergic terminals that contain VGluT1 (cii, cyan) and VGluT2 (dii, magenta). Note that almost all of the glutamatergic terminals on this cell contain both VGluT1 and VGluT2 as confirmed in eii, where terminals labeling for VGluT1 + VGluT2 are shown as white spots. eii also shows that the white spots (VGluT1 + VGluT2 terminals) form ellipsoids with the green spots (nNOS puncta), indicating that they are in close proximity to each other. DAPI-stained nuclei are shown in gray. Scale bars: $\boldsymbol{a}, \boldsymbol{b}$, $10 \mu \mathrm{m} ; c-e, 2 \mu \mathrm{m}$.

nNOS with GABA and glycine terminals, we also used an antibody against VGAT, the GABA and glycine vesicular transporter.

Confocal imaging and image analysis using Imaris revealed three populations of presumed glutamatergic terminals in the ICC: some terminals had labeling for VGluT1 only, others labeled for VGluT2 only, and a third population had labeling for both VGluT1 and VGluT2 within the same terminal. We classified a terminal as "VGluT1 + VGluT2" when VGluT1 + VGluT2 spots occurred within $0.1 \mu \mathrm{m}$ of each other.

We saw all three patterns of labeling around neurons containing nNOS puncta in the ICc (Fig. 3a). VGluT2-only terminals were particularly abundant, but nNOS spots were rarely close to these terminals (only $3 \pm 3 \%$ were within a $0.6-\mu \mathrm{m}$-diameter sphere). VGluT1-only terminals were less abundant and again nNOS spots were rarely close to them (only $5 \pm 2 \%$ were within a $0.6 \mu \mathrm{m}$ diameter sphere). Although many VGluT1 + VGluT2 terminals were not associated with nNOS puncta, intriguingly, almost all nNOS puncta
$(89 \pm 3 \%)$ coincided with terminals labeling for VGluT1 + VGluT2 (Fig. 3cii,dii,eii). Many neurons expressing nNOS puncta also had VGAT-labeled terminals around them (Fig. $3 b$ ). However, proximity testing in Imaris never showed any association between puncta labeled for nNOS and VGAT.

These findings provide evidence that nNOS puncta in the ICC are associated with NMDA-Rs, sGC, and PSD95 and occur at glutamatergic synapses with presynaptic terminals of fibers expressing both VGluT1 and VGluT2.

nNOS puncta in the ICC are functional and mediate the effects of NMDA-R activation

Our immunohistochemical studies demonstrated that punctate nNOS forms a multiprotein complex with NMDA-R and sGC anchored to PSD95. This suggests that stimulation of these NMDA-Rs should lead to the production of NO, which in turn should activate its receptor, $\mathrm{sGC}$, to produce cGMP. If this is the 
a
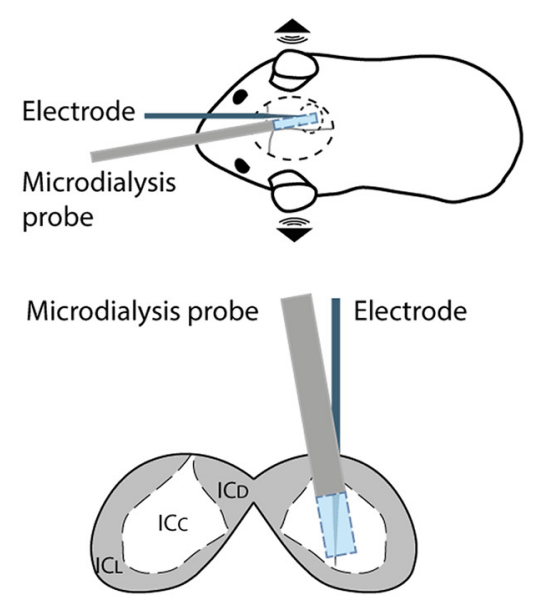

b

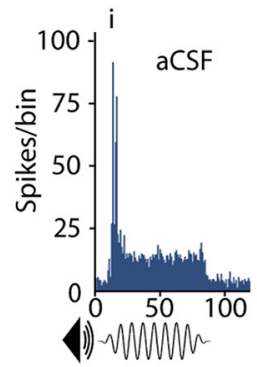

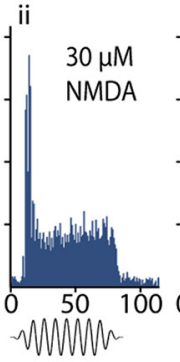

C

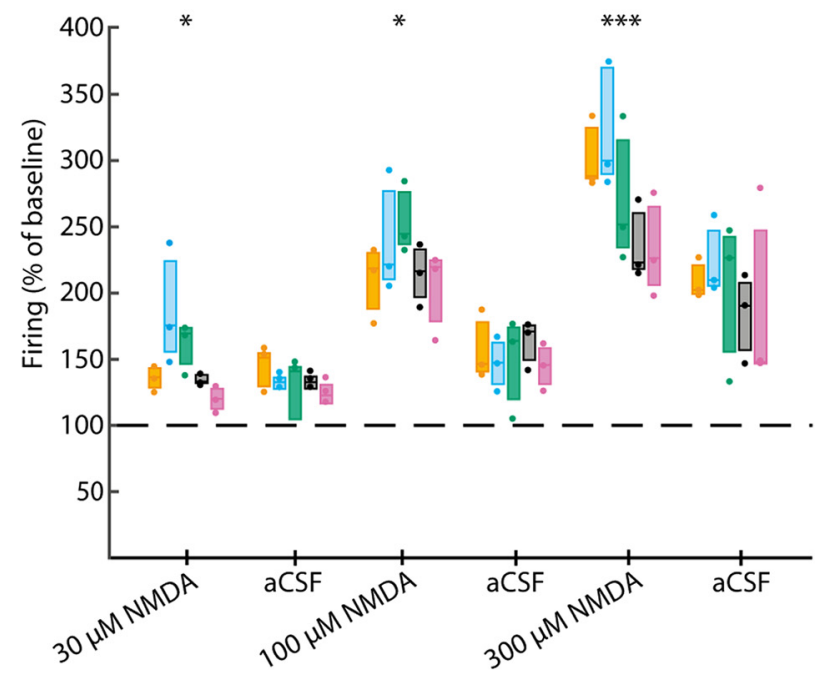

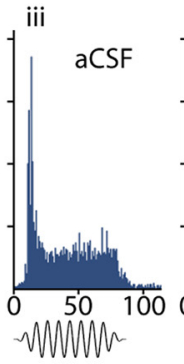

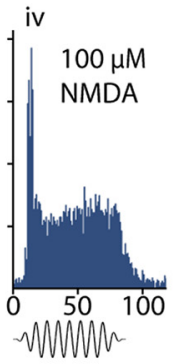

Time (ms)
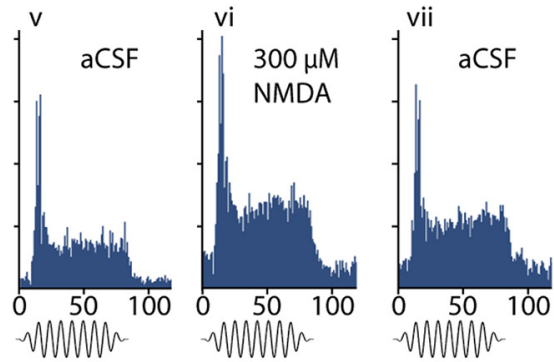

Figure 4. NMDA-R activation increases sound-driven activity in the ICc in a concentration-dependent and reversible manner. $\boldsymbol{a}$, Top, Anesthetized guinea pigs were implanted with a microdialysis probe and a 32-channel linear recording probe; sound stimuli were delivered to the ears through a closed acoustic system. Bottom, Schematic coronal section through the IC showing the relative positions of the microdialysis probe and the electrode in the IC. $\boldsymbol{b} \boldsymbol{i}$ - $\boldsymbol{b} v \boldsymbol{i i}$, Example PSTHs of responses to $1024 \mathrm{~Hz}$ tone burst ( $75 \mathrm{~ms}$ duration) during baseline (bi, aCSF) and local perfusion of NMDA at three different concentrations (bii, 30; $\boldsymbol{b i v}, 100$; and $\boldsymbol{b} \boldsymbol{v i}, 300 \mu \mathrm{M}$ ) with aCSF washouts (biii, $\boldsymbol{b} \boldsymbol{v}$, and $\boldsymbol{b} v \boldsymbol{i i}$ ). Note that the peak of activity at the onset of the sound stimulus and the lower sustained activity during the remainder of the stimulus. NMDA increased the response throughout the stimulus in a concentration-dependent manner. $\boldsymbol{c}$, Group data derived from PSTHs (as in $\boldsymbol{b}$ ) revealing that local application of NMDA increased sound-driven activity recorded from all of the individual electrode sites with the greatest responses to 256,512,1024,2048, and $4096 \mathrm{~Hz}$. NMDA $(30,100$, and $300 \mu \mathrm{M})$ increased the response in a concentration-dependent manner at all frequencies and this effect partially reversed on washout. Data show firing recorded $20 \mathrm{~min}$ after the start of NMDA perfusion and for the washout blocks 40 min after perfusion of aCSF. $n=3$ animals. ${ }^{*} p<0.05$; ${ }^{* * *} p<0.001$, paired sample $t$ test planned post hoc comparison, Sidak corrected for multiple comparisons following significant ANOVA. Box plots show median and interquartile range together with individual data points.

case, then inhibition of nNOS or sGC might modulate neuronal responses to NMDA in the ICC. To test this prediction, we conducted electrophysiological recordings in the ICc.

In anesthetized guinea pigs, we used multi-site electrodes to record neuronal activity along the tonotopic axis of the ICC in response to sound. Simultaneously, we delivered drugs targeting NMDA-Rs, nNOS, and sGC in the vicinity of the electrodes using microdialysis (Fig. $4 a$; see Materials and Methods). Pure tone stimuli ( $75 \mathrm{~ms}$ in duration) were presented at frequencies of 256, 512, 1024, 2048, and $4096 \mathrm{~Hz}$. PSTHs constructed from multiunit activity recorded at the five electrode positions maximally activated by these five frequencies (Fig. $4 b$ ) typically showed a marked increase in firing with a latency of $\sim 10 \mathrm{~ms}$ corresponding to the onset of the tone, followed by a sustained, lower elevation in firing for the remainder of the tone duration.

First, we demonstrated that NMDA delivered to the ICC influences sound-driven responses in a concentration-dependent manner. After a baseline recording during which aCSF alone was perfused (Fig. 4bi), we delivered NMDA in increasing concentrations $(30,100$, and $300 \mu \mathrm{M})$ (Fig. 4 bii, biv, bvi) with a washout period of aCSF between each drug application (Fig. 4biii,bvii). As the concentration of NMDA was increased, there was a concomitant increase in the sound-driven activity recorded at all frequency locations (Fig. 4c, Table 1). The effect of NMDA was maximal after $20 \mathrm{~min}$ and progressively reversed over the course of 40-50 min, during which the NMDA was washed out, although reversal was incomplete after the highest concentration of NMDA (Fig. 4bvii,c). NMDA also increased spontaneous activity in a concentration-dependent manner (Table 1; see also the 10 ms pre-response period in Fig. 4bii,biv, bvi). Note, however, that spontaneous activity was 5-10 times below the level of sounddriven activity (Table 1).

Subjecting the data shown in Figure $4 c$ to a two-way repeatedmeasures ANOVA revealed a significant main effect of drug condition $\left(F_{(6,12)}=131.2, p<0.0001\right)$, but no main effect of frequency $\left(F_{(4,8)}=1.4\right.$, n.s. $)$ and no significant condition $\times$ frequency interaction $\left(F_{(24,48)}=1.1\right.$, n.s.). Activity levels induced by all concentrations of NMDA were significantly different from baseline (average across all frequencies, percentage of baseline \pm SEM: $30 \mu \mathrm{M}, 148.0 \pm 3.9 \%, p=0.018 ; 100 \mu \mathrm{M}, 225.5 \pm 10.1 \%$, 
Table 1. Effect of increasing concentrations of NMDA on spontaneous and sounddriven activity

\begin{tabular}{|c|c|c|c|c|c|c|}
\hline & \multicolumn{2}{|l|}{$256 \mathrm{~Hz}$} & \multicolumn{2}{|l|}{$512 \mathrm{~Hz}$} & \multicolumn{2}{|l|}{$1024 \mathrm{~Hz}$} \\
\hline & Spontaneous & Driven & Spontaneous & Driven & Spontaneous & Driven \\
\hline $\mathrm{aCSF}$ & $6.6 \pm 1.9$ & $46.2 \pm 28.1$ & $6.8 \pm 0.3$ & $48.4 \pm 22.6$ & $7.3 \pm 0.9$ & $49.9 \pm 39.6$ \\
\hline $30 \mu \mathrm{M} N M D A$ & $7.5 \pm 4.1$ & $62.4 \pm 36.3$ & $7.8 \pm 3.5$ & $93.7 \pm 48.5$ & $10.1 \pm 3.0$ & $82.6 \pm 69.5$ \\
\hline aCSF & $8.7 \pm 5.7$ & $66.1 \pm 43.4$ & $8.1 \pm 2.5$ & $65.0 \pm 32.6$ & $8.9 \pm 1.9$ & $66.7 \pm 59.9$ \\
\hline $100 \mu \mathrm{M}$ NMDA & $14.6 \pm 7.0$ & $92.4 \pm 49.0$ & $12.3 \pm 1.9$ & $118.4 \pm 57.5$ & $15.6 \pm 2.9$ & $125.2 \pm 94.9$ \\
\hline $\mathrm{aCSF}$ & $10.3 \pm 4.9$ & $68.2 \pm 35.4$ & $6.8 \pm 2.2$ & $72.8 \pm 41.5$ & $11.1 \pm 3.3$ & $81.2 \pm 77.7$ \\
\hline $300 \mu \mathrm{M}$ NMDA & $23.0 \pm 12.0$ & $135.4 \pm 76.9$ & $16.7 \pm 3.3$ & $159.8 \pm 76.1$ & $21.8 \pm 8.0$ & $131.6 \pm 96.3$ \\
\hline \multirow[t]{3}{*}{$\mathrm{aCSF}$} & $18.5 \pm 16.5$ & $94.2 \pm 54.7$ & $9.5 \pm 2.0$ & $113.0 \pm 66.2$ & $13.7 \pm 2.2$ & $106.8 \pm 97.0$ \\
\hline & \multicolumn{3}{|c|}{$2048 \mathrm{~Hz}$} & \multicolumn{3}{|c|}{$4096 \mathrm{~Hz}$} \\
\hline & \multicolumn{2}{|c|}{ Spontaneous } & Driven & \multicolumn{2}{|c|}{ Spontaneous } & Driven \\
\hline $\mathrm{aCSF}$ & \multicolumn{2}{|c|}{$7.8 \pm 3.4$} & $63.6 \pm 35.1$ & \multicolumn{2}{|c|}{$6.7 \pm 4.1$} & $55.9 \pm 20.5$ \\
\hline $30 \mu \mathrm{M}$ NMDA & \multicolumn{2}{|c|}{$12.1 \pm 6.6$} & $86.1 \pm 46.9$ & \multicolumn{2}{|c|}{$9.1 \pm 6.8$} & $68.9 \pm 30.7$ \\
\hline $\mathrm{aCSF}$ & \multicolumn{2}{|c|}{$12.9 \pm 6.6$} & $85.0 \pm 47.4$ & \multicolumn{2}{|c|}{$13.7 \pm 12.8$} & $69.8 \pm 26.5$ \\
\hline $100 \mu \mathrm{M}$ NMDA & \multicolumn{2}{|c|}{$18.8 \pm 10.3$} & $142.6 \pm 91.9$ & \multicolumn{2}{|c|}{$16.5 \pm 10.3$} & $117.5 \pm 54.8$ \\
\hline $\mathrm{aCSF}$ & \multicolumn{2}{|c|}{$13.0 \pm 8.8$} & $100.5 \pm 44.9$ & \multicolumn{2}{|c|}{$10.6 \pm 6.7$} & $79.7 \pm 22.7$ \\
\hline $300 \mu \mathrm{M}$ NMDA & \multicolumn{2}{|c|}{$25.5 \pm 16.2$} & $157.8 \pm 106.8$ & \multicolumn{2}{|c|}{$19.6 \pm 10.7$} & $136.9 \pm 72.7$ \\
\hline $\mathrm{aCSF}$ & \multicolumn{2}{|c|}{$17.3 \pm 10.8$} & $110.7 \pm 44.7$ & \multicolumn{2}{|c|}{$13.4 \pm 7.6$} & $105.8 \pm 46.9$ \\
\hline
\end{tabular}

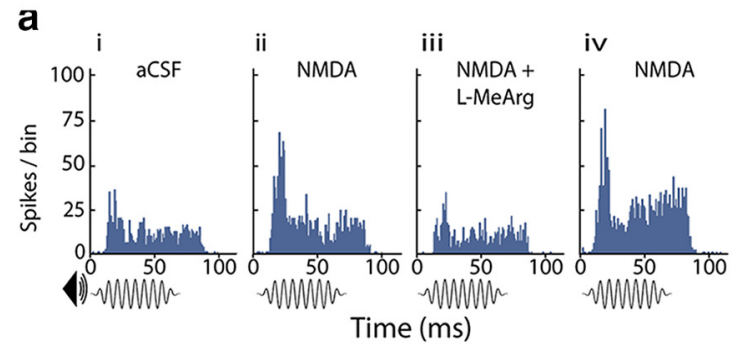

b

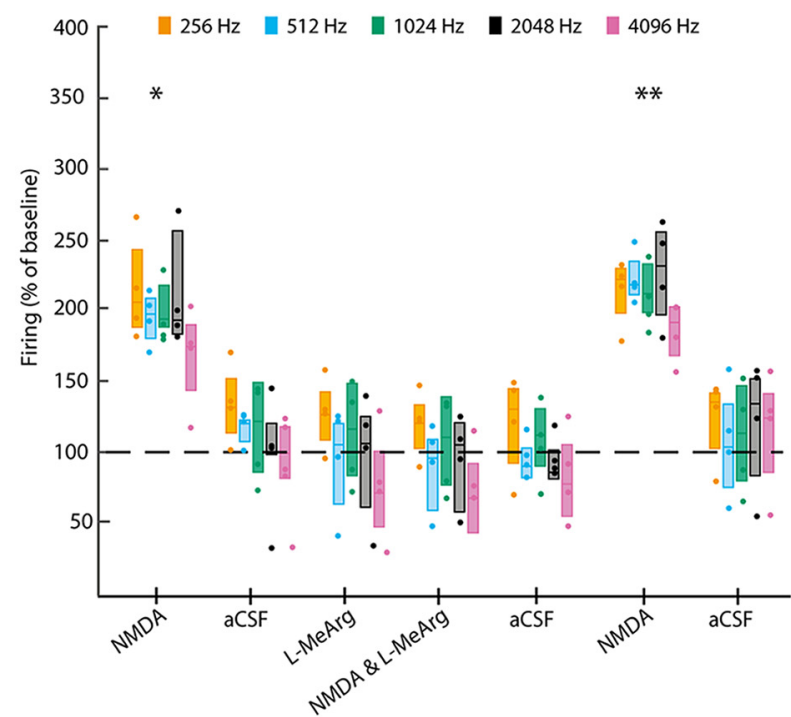

$p=0.018 ; 300 \mu \mathrm{M}, 275.4 \pm 2.1 \%, p=0.0003$, post hoc $t$ test with Sidak correction for multiple comparisons).

\section{NMDA-evoked activation of the ICC is mediated by nNOS}

To test whether the NMDA-evoked increase in sound-driven activity seen in the previous experiment is mediated by NO, we combined perfusion of NMDA with perfusion of the reversible nNOS inhibitor L-MeArg. Based on the previous experiment, we chose an NMDA concentration of $100 \mu \mathrm{M}$ for this because it elicited a robust and readily reversible increase in sound-driven activity.

As before, NMDA $(100 \mu \mathrm{M})$ evoked an increase in sounddriven activity at all frequencies (Fig. 5aii,b) and this reversed during washout (Fig. 5b). Next, we applied L-MeArg (1 mM) immediately followed by L-MeArg (1 mM) in combination with NMDA $(100 \mu \mathrm{M})$. In the presence of L-MeArg alone, sounddriven activity was unaffected at any of the frequencies tested (Fig. 5b). Remarkably, when L-MeArg was applied along with NMDA, NMDA failed to elicit any increase in firing (Fig. 5aiii,b). To verify that neurons were still capable of responding to NMDA after L-MeArg washed out, we perfused NMDA (100 $\mu \mathrm{M})$ alone. Again we observed the expected large increase in sound-driven activity (Fig. 5aiv).
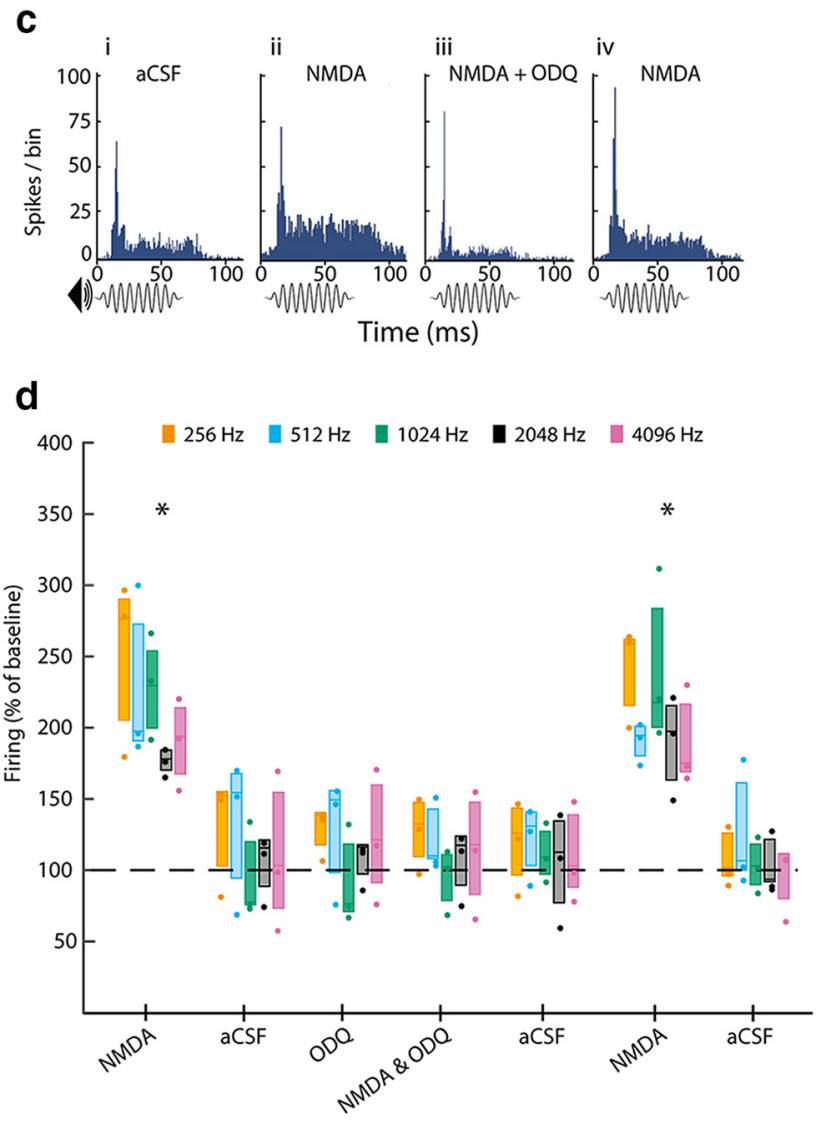

Figure 5. The effect of NMDA is blocked by the inhibition of nNOS and SGC. $\boldsymbol{a}$, Example PSTHs of the response to $1024 \mathrm{~Hz}$ tone-bursts during (ai) baseline (aCSF) and perfusion of ( $\boldsymbol{a i i}$ ) NMDA $(100 \mu \mathrm{M})$ and (aiii) NMDA combined with L-MeArg $(1 \mathrm{mM})$. Washout and $\mathrm{L}-\mathrm{MeArg}$ alone blocks are not shown. Note that, in aiii, NMDA fails to increase sound-driven activity in the presence of L-MeArg, but in aiv, its effect is restored after washout of L-MeArg. $\boldsymbol{b}$, Group data $(n=4)$ derived from PSTHs (as in $\boldsymbol{a})$ for all frequencies. Perfusion of NMDA (100 $\mu \mathrm{M}$ ) increased sound-driven activity at all frequencies. L-MeArg alone had no effect on sound-driven activity, but blocked the response to NMDA. Following washout of $\mathrm{L}-\mathrm{Me}$ Arg, NMDA again increased sound-driven activity. c, Example PSTHs of the response to $1024 \mathrm{~Hz}$ tone-bursts during (ci) baseline (aCSF) and perfusion of (cii) NMDA (100 $\mu \mathrm{M}$ ) and (ciii) NMDA combined with the SGC inhibitor ODQ $(500 \mu \mathrm{m})$. Washout and ODQ-alone blocks are not shown. Note that, in ciii, NMDA fails to increase sound-driven activity in the presence of ODQ, but in civ, its effect is restored after washout of ODQ. $\boldsymbol{d}$, Group data $(n=3)$ derived from PSTHs (as in c) for all frequencies. Perfusion of NMDA (100 $\mu$ ) increased the sound-driven activity at all frequencies. ODQ alone had no effect, but blocked the response to NMDA. Following washout of ODQ, NMDA again increased sound-driven activity. Data show firing recorded 20 min after the start of drug perfusion or 40 min after the start of aCSF perfusion. ${ }^{*} p<0.05 ;{ }^{* *} p<0.01$, paired-sample $t$ test planned post hoc comparison Sidak corrected for multiple comparisons following significant ANOVA. Box plots show median and interquartile range together with individual data points. 
Two-way repeated-measures ANOVA confirmed a significant main effect of drug condition $\left(F_{(7,21)}=17.6, p<\right.$ $0.0001)$, but no significant main effect of frequency $\left(F_{(4,12)}=1.4\right.$, n.s. $)$ and no significant condition $X$ frequency interaction $\left(F_{(28,84)}=2.1\right.$, n.s. $)$. Post hoc $t$ tests, Sidak corrected, showed that both the initial and final NMDA-alone conditions averaged across all frequencies were significantly different from baseline $(217.0 \pm$ $16.3 \%, p=0.022$ and $231.7 \pm 7.01 \%, p=$ 0.0013 , respectively), whereas the L-MeArg alone and L-MeArg + NMDA conditions were not significantly different from baseline (103.5 $\pm 19.1 \%$, n.s., and $95.8 \pm 17.5 \%$, n.s., respectively).

These data are consistent with our hypothesis that modulation of sound-driven activity by the activation of NMDA-Rs in the ICC is mediated by the stimulation of nNOS, leading to the synthesis of NO.

\section{NMDA-evoked activation of the ICC is mediated by sGC}

Finally, we addressed whether the nNOSdependent response to NMDA observed above also requires the activation of sGC. To examine this, we combined application of NMDA with perfusion of the sGC inhibitor ODQ. Initial perfusion of NMDA $(100 \mu \mathrm{M})$ evoked an increase in sound-driven activity (Fig. $5 c i i, d$ ), which reversed on washout. Next, we perfused ODQ $(500 \mu \mathrm{M})$ alone (Fig. $5 d$ ) before perfusing NMDA in combination with ODQ (Fig. 5ciii,d). Sound-driven activity was unaffected by ODQ alone (Fig. $5 d$ ) and, when ODQ was applied along with NMDA, NMDA failed to elicit any increase in firing (Fig. 5ciii,d). Finally, following ODQ washout, a further perfusion of NMDA alone elicited the expected large increase in sound-driven activity (Fig. 5 civ, $d$ ).

A two-way repeated-measures ANOVA confirmed a significant main effect of drug condition $\left(F_{(7,14)}=21.4, p<0.0001\right)$, no significant main effect of frequency $\left(F_{(4,8)}=3.8\right.$, n.s. $)$, and no significant condition $\times$ frequency interaction $\left(F_{(28,56)}=1.1\right.$, n.s.). Post hoc $t$ tests, Sidak corrected, showed that both the initial and the final NMDA-alone conditions averaged across all frequencies were significantly different from baseline (232.5 \pm $14.9 \%, p=0.050$, and $231.2 \pm 12.4 \%, p=0.035$, respectively), whereas the ODQ alone and ODQ with NMDA conditions were not significantly different from baseline $(113.0 \pm 14.9 \%$, n.s., and $110.8 \pm 8.8 \%$, n.s., respectively).

\section{Discussion}

Here, we report punctate expression of nNOS in the IC and demonstrate its functional involvement in auditory processing in vivo. $\mathrm{nNOS}$ expression in the IC is more extensive than previously reported: in addition to cytoplasmically labeled nNOS neurons in the IC cortices, nNOS also occurs in the ICC, where it is in the form of puncta. Virtually all of these nNOS puncta are associated with NMDA-R, sGC, and PSD95 and apposed to glutamatergic terminals suggesting a postsynaptic multiprotein complex that mediates NMDA-R signaling through the production of NO. The importance of NMDA-R and NO signaling in ICC was revealed by in vivo experiments that demonstrate the increase in sound- driven neuronal firing by NMDA is completely inhibited by blockade of either nNOS or sGC.

\section{Two distinct patterns of nNOS in the IC}

The nNOS expression that we report in the cortices of the IC is consistent with previous studies showing that neurons with diffuse cytoplasmic labeling are abundant in these subdivisions (Herbert et al., 1991; Druga and Syka, 1993; Coote and Rees, 2008; Hinova-Palova et al., 2017). However, we found nNOS puncta in neurons located in all three subdivisions of the IC. Importantly, vast numbers of nNOS puncta are found in the ICC. Indeed, virtually all neurons in the ICC, both glutamatergic and GABAergic, contain nNOS puncta. The ubiquitous presence of nNOS in neurons in the ICc may previously have gone unnoticed because it occurs in the form of puncta not visible at low magnification. Interestingly, a recent study addressing developmental changes in mouse brain included a low-power image in which punctate nNOS labeling in the ICC was apparent (Fujimoto et al., 2017), although this was not noted or discussed.

\section{nNOS puncta are structurally associated with PSD95 and with} NMDA-R and sGC

In several brain regions, the NMDA-R has been linked to NO signaling. Given that $\mathrm{Ca}^{2+}$ entry via NMDA-Rs is highly localized and that NO is only synthesized in picomolar concentrations, it has been postulated that the proteins in this pathway must be in close proximity (Garthwaite, 2008). Previous studies (Kornau et al., 1995; Brenman et al., 1996; Niethammer et al., 1996; Russwurm et al., 2001) showed that nNOS, NMDA-R, and sGC can all potentially interact with PSD95. Until now, however, the formation of a multiprotein complex involving all four proteins had not been demonstrated in native tissue. Using quadruple immunohistochemistry, we revealed that virtually all nNOS puncta in the 
ICC occur close to PSD95, NMDA-R, and sGC, confirming that nNOS in the IC exists as part of this multiprotein complex. To the best of our knowledge, this is the first time that all four proteins have been demonstrated to occur simultaneously at the same postsynaptic site, as illustrated schematically in Figure 6.

In contrast, neurons with cytoplasmic labeling for nNOS in the cortices of the IC are not associated with the proteins that constitute the multiprotein complex at nNOS puncta. This suggests a less temporally and spatially specific mode of action of NO in these neurons, perhaps by volume transmission, as has been shown to occur elsewhere in the auditory pathway (Steinert et al., 2008).

\section{nNOS puncta are innervated by glutamatergic terminals}

We found that nNOS puncta at the cell membrane of neurons occur in close apposition to glutamatergic terminals, indicating that they are situated in synapses and likely to be functionally active. A previous report showed punctate nNOS in the hippocampus located on dendritic spines receiving glutamatergic inputs (Burette et al., 2002), as well as occasionally bound to the post synaptic densities of GABAergic synapses (Szabadits et al., 2007). In the IC, we found that nNOS puncta are almost exclusively associated with glutamatergic presynaptic terminals identified by the presence of vesicular glutamate transporter proteins (Fremeau et al., 2001; Kaneko and Fujiyama, 2002) and never with GABAergic or glycinergic terminals.

The expression of VGluT1 + VGluT2 in the terminals of fibers in the ICc helps to reveal their origin (Ito and Oliver, 2010; Ito et al., 2011). Terminals containing exclusively VGluT1 originate predominantly from the cerebral cortex, whereas terminals containing only VGluT2 represent intracollicular connections, along with ascending inputs from the dorsal cochlear nucleus, some nuclei in the superior olive, and the lateral lemniscus (Ito and Oliver, 2010). Terminals containing both VGluT1 and VGluT2 belong to fibers originating from three principal sources in the brainstem: the contralateral ventral cochlear nucleus $(\mathrm{VCN})$, the ipsilateral medial superior olivary nucleus (MSO), and certain subdivisions of the periolivary nuclei (Ito and Oliver, 2010).

We cannot specify the sources giving rise to the VGluT1 + VGluT2 terminals associated with the nNOS puncta and there are indeed many VGluT1 + VGluT2 terminals that are not associated with nNOS puncta. However, it seems unlikely that precisely timed inputs from the MSO (which signal interaural time differences; Grothe et al., 2010) would terminate at synapses with "slowly" responding NMDA-Rs. More likely, these terminals originate from the type 1 multipolar (or T-stellate) neurons in the VCN (Cant and Benson, 2003, 2006) that signal information about the spectrum of sounds (Young et al., 1988; Blackburn and Sachs, 1989, 1990; Oertel et al., 2011). If type 1 multipolar neurons signal through NMDA-Rs in the ICC, then they could mediate some form of neuronal plasticity.

Potential physiological role of $\mathrm{nNOS} / \mathrm{sGC}$ signaling in the ICC Our electrophysiological data show the important influence that NO signaling can have in the ICC. Local perfusion of NMDA in the ICC resulted in a substantial and concentration-dependent increase in sound-driven activity. Remarkably, this NMDAevoked increase in activity was completely blocked when we inhibited nNOS or sGC. These effects are likely to originate in the ICc because substances infused by microdialysis are spatially limited to $\sim 1.5 \mathrm{~mm}$ from the probe (Boehnke and Rasmusson, 2001). Furthermore, because neurons in the IC cortices do not project back to the ICC, indirect effects from those subdivisions are unlikely.

Sound stimuli drive neuronal activity in the ICc via multiple parallel excitatory and inhibitory inputs (Oliver, 2005). Glutamatergic inputs have been shown to be mediated by both AMPA and NMDA-Rs (Faingold et al., 1989; Zhang and Kelly, 2001) and it is perhaps surprising that blocking nNOS and sGC had no effect on endogenous glutamatergic signaling in response to sound. Prosaic reasons relating to the time course and concentration of drug application or sensitivity of our measure could explain this finding, but it is interesting that, with a different method in a different structure, Yassin et al. (2014) similarly found no effect of ODQ when it was applied alone.

It should be noted that, whereas most NMDA-Rs on the somata are linked to nNOS, we found many NMDA-Rs, particularly on the dendrites, that were not linked to nNOS. The influence of the latter population on sound-driven activity should not be blocked by L-MeArg or ODQ. Thus, these two populations of NMDA-Rs may be activated under different conditions and serve different functions.

\section{Is there a role for NMDA-Rs and nNOS in adaptive and maladaptive changes?}

The modulation of neuronal signaling in the ICC through the activation of NMDA-Rs and nNOS suggests that these mechanisms may mediate adaptive or plastic changes in response to sound (Slee and David, 2015). The auditory system is highly plastic and evidence suggests that the IC is particularly so (Yan and Suga, 1998; Suga and Ma, 2003). Sustained NMDA-R activation subsequent to stimulus or neuromodulatory input will activate nNOS and lead to production of cGMP. Via protein kinase G, cGMP induces phosphorylation of AMPA receptor subunits and thereby influences the insertion of AMPA receptors into the cell membrane (Serulle et al., 2007; Incontro et al., 2013; Song et al., 2016). This mechanism would enhance neuronal excitability and might underlie the increase in sound-driven activity we observed following NMDA perfusion. In some circumstances, changes in nNOS expression may be maladaptative. Thus, increases in neuronal excitability and firing that occur in the IC following acoustic trauma (Mulders and Robertson, 2009) or salicylate (Patel and Zhang, 2014; Olthof-Bakker et al., 2017) could depend on the upregulation of nNOS, as has been demonstrated in the cochlear nucleus in similar animal models of tinnitus (Zheng et al., 2006; Coomber et al., 2015).

\section{Wider implications}

The discovery of extensive punctate nNOS expression in the ICC has important implications for our understanding of neuronal mechanisms of sound processing in the IC and the auditory pathway. However, these findings also have implications beyond the auditory system. The discovery of nNOS puncta in a region previously thought to be devoid of nNOS highlights the fact that nNOS expression, and by extension NO signaling, may have gone unnoticed in other brain regions. Our finding of two distinct subcellular distributions may lead to a new understanding of how NO contributes to neuronal processing.

\section{References}

Arnold WP, Mittal CK, Katsuki S, Murad F (1977) Nitric oxide activates guanylate cyclase and increases guanosine $3^{\prime}: 5^{\prime}$-cyclic monophosphate levels in various tissue preparations. Proc Natl Acad Sci U S A 74:32033207. CrossRef Medline

Bellefontaine N, Chachlaki K, Parkash J, Vanacker C, Colledge W, d'Anglemont de Tassigny X, Garthwaite J, Bouret SG, Prevot V (2014) 
Leptin-dependent neuronal no signaling in the preoptic hypothalamus facilitates reproduction. J Clin Invest 124:2550-2559. CrossRef Medline

Blackburn CC, Sachs MB (1989) Classification of unit types in the anteroventral cochlear nucleus: pst histograms and regularity analysis. J Neurophysiol 62:1303-1329. CrossRef Medline

Blackburn CC, Sachs MB (1990) The representations of the steady-state vowel sound /e/ in the discharge patterns of cat anteroventral cochlear nucleus neurons. J Neurophysiol 63:1191-1212. CrossRef Medline

Boehnke SE, Rasmusson DD (2001) Time course and effective spread of lidocaine and tetrodotoxin delivered via microdialysis: an electrophysiological study in cerebral cortex. J Neurosci Methods 105:133-141. CrossRef Medline

Brenman JE, Chao DS, Gee SH, McGee AW, Craven SE, Santillano DR, Wu Z, Huang F, Xia H, Peters MF, Froehner SC, Bredt DS (1996) Interaction of nitric oxide synthase with the postsynaptic density protein PSD-95 and $\alpha 1$-syntrophin mediated by PDZ domains. Cell 84:757-767. CrossRef Medline

Burette A, Zabel U, Weinberg RJ, Schmidt HH, Valtschanoff JG (2002) Synaptic localization of nitric oxide synthase and soluble guanylyl cyclase in the hippocampus. J Neurosci 22:8961-8970. CrossRef Medline

Cant NB, Benson CG (2003) Parallel auditory pathways: projection patterns of the different neuronal populations in the dorsal and ventral cochlear nuclei. Brain Res Bull 60:457-474. CrossRef Medline

Cant NB, Benson CG (2006) Organization of the inferior colliculus of the gerbil (Meriones unguiculatus): differences in distribution of projections from the cochlear nuclei and the superior olivary complex. J Comp Neurol 495:511-528. CrossRef Medline

Coomber B, Kowalkowski VL, Berger JI, Palmer AR, Wallace MN (2015) Modulating central gain in tinnitus: Changes in nitric oxide synthase in the ventral cochlear nucleus. Front Neurol 6:53. CrossRef Medline

Coote EJ, Rees A (2008) The distribution of nitric oxide synthase in the inferior colliculus of guinea pig. Neuroscience 154:218-225. CrossRef Medline

Cudeiro J, Rivadulla C, Rodriguez R, Martinez-Conde S, Acuña C, Alonso JM (1994) Modulatory influence of putative inhibitors of nitric-oxide synthesis on visual processing in the cat lateral geniculate- nucleus. J Neurophysiol 71:146-149. CrossRef Medline

Druga R, Syka J (1993) NADPH-diaphorase activity in the central auditory structures of the rat. Neuroreport 4:999-1002. CrossRef Medline

Endoh M, Maiese K, Wagner JA (1994) Expression of the neural form of nitric oxide synthase by cal hippocampal neurons and other central nervous system neurons. Neuroscience 63:679-689. CrossRef Medline

Faingold CL, Hoffmann WE, Caspary DM (1989) Effects of excitant amino acids on acoustic responses of inferior colliculus neurons. Hear Res 40: 127-136. CrossRef Medline

Faye-Lund H, Osen KK (1985) Anatomy of the inferior colliculus in rat. Anat Embryol (Berl) 171:1-20. CrossRef

Feelisch M, Martin JF (1995) The early role of nitric oxide in evolution. Trends Ecol Evol 10:496-499. CrossRef Medline

Fremeau RT Jr, Troyer MD, Pahner I, Nygaard GO, Tran CH, Reimer RJ, Bellocchio EE, Fortin D, Storm-Mathisen J, Edwards RH (2001) The expression of vesicular glutamate transporters defines two classes of excitatory synapse. Neuron 31:247-260. CrossRef Medline

Fujimoto H, Konno K, Watanabe M, Jinno S (2017) Late postnatal shifts of parvalbumin and nitric oxide synthase expression within the gabaergic and glutamatergic phenotypes of inferior colliculus neurons. J Comp Neurol 525:868-884. CrossRef Medline

Garthwaite J (2008) Concepts of neural nitric oxide-mediated transmission. Eur J Neurosci 27:2783-2802. CrossRef Medline

Garthwaite J (2016) From synaptically localized to volume transmission by nitric oxide. J Physiol 594:9-18. CrossRef Medline

Garthwaite J, Charles SL, Chess-Williams R (1988) Endothelium-derived relaxing factor release on activation of NMDA receptors suggests role as intercellular messenger in the brain. Nature 336:385-388. CrossRef Medline

Grothe B, Pecka M, McAlpine D (2010) Mechanisms of sound localization in mammals. Physiol Rev 90:983-1012. CrossRef Medline

Hardingham N, Fox K (2006) The role of nitric oxide and GluR1 in presynaptic and postsynaptic components of neocortical potentiation. J Neurosci 26:7395-7404. CrossRef Medline

Hardingham N, Dachtler J, Fox K (2013) The role of nitric oxide in pre- synaptic plasticity and homeostasis. Front Cell Neurosci 7:190. CrossRef Medline

Herbert H, Aschoff A, Ostwald J (1991) Topography of projections from the auditory cortex to the inferior colliculus in the rat. J Comp Neurol 304: 103-122. CrossRef Medline

Hinova-Palova D, Landzhov B, Dzhambazova E, Edelstein L, Minkov M, Fakih K, Minkov R, Paloff A, Ovtscharoff W (2017) NADPHdiaphorase-positive neurons in the human inferior colliculus: morphology, distribution and clinical implications. Brain Struct Funct 222: 1829-1846. CrossRef Medline

Iannone M, DelDuca C, Granato T, Rispoli V, Nisticò G (1996) Soundevoked electrocortical desynchronization is inhibited by $\mathrm{n}$ omega-nitrol-arginine methyl ester microinfused into the inferior colliculi in rats. Electroencephalogr Clin Neurophysiol 99:57-62. CrossRef Medline

Incontro S, Ciruela F, Ziff E, Hofmann F, Sánchez-Prieto J, Torres M (2013) The type II cGMP dependent protein kinase regulates GluA1 levels at the plasma membrane of developing cerebellar granule cells. Biochim Biophys Acta 1833:1820-1831. CrossRef Medline

Ito T, Oliver DL (2010) Origins of glutamatergic terminals in the inferior colliculus identified by retrograde transport and expression of VGLUT1 and VGLUT2 genes. Front Neuroanat 4:135. CrossRef Medline

Ito T, Bishop DC, Oliver DL (2011) Expression of glutamate and inhibitory amino acid vesicular transporters in the rodent auditory brainstem. J Comp Neurol 519:316-340. CrossRef Medline

Kaneko T, Fujiyama F (2002) Complementary distribution of vesicular glutamate transporters in the central nervous system. Neurosci Res 42:243250. CrossRef Medline

Kopp-Scheinpflug C, Pigott BM, Forsythe ID (2015) Nitric oxide selectively suppresses $\mathrm{I}_{\mathrm{H}}$ currents mediated by HCN1-containing channels. J Physiol 593:1685-1700. CrossRef Medline

Kornau HC, Schenker LT, Kennedy MB, Seeburg PH (1995) Domain interaction between NMDA receptor subunits and the postsynaptic density protein PSD-95. Science 269:1737-1740. CrossRef Medline

Lima MG, Maximino C, Matos Oliveira KR, Brasil A, Crespo-Lopez ME, Batista Ede J, Rocha FA, Picanço-Diniz DL, Herculano AM (2014) Nitric oxide as a regulatory molecule in the processing of the visual stimulus. Nitric Oxide 36:44-50. CrossRef Medline

Merchán M, Aguilar LA, Lopez-Poveda EA, Malmierca MS (2005) The inferior colliculus of the rat: quantitative immunocytochemical study of GABA and glycine. Neuroscience 136:907-925. CrossRef Medline

Moroz LL, Kohn AB (2011) Parallel evolution of nitric oxide signaling: diversity of synthesis and memory pathways. Front Biosci (Landmark Ed) 16:2008-2051. CrossRef Medline

Mulders WH, Robertson D (2009) Hyperactivity in the auditory midbrain after acoustic trauma: dependence on cochlear activity. Neuroscience 164:733-746. CrossRef Medline

Niethammer M, Kim E, Sheng M (1996) Interaction between the c terminus of NMDA receptor subunits and multiple members of the PSD-95 family of membrane-associated guanylate kinases. J Neurosci 16:2157-2163. CrossRef Medline

O’Dell TJ, Hawkins RD, Kandel ER, Arancio O (1991) Tests of the roles of two diffusible substances in long-term potentiation: evidence for nitric oxide as a possible early retrograde messenger. Proc Natl Acad Sci U S A 88:11285-11289. CrossRef Medline

Oertel D, Wright S, Cao XJ, Ferragamo M, Bal R (2011) The multiple functions of T stellate/multipolar/chopper cells in the ventral cochlear nucleus. Hear Res 276:61-69. CrossRef Medline

Oliver DL (2005) Neuronal organisation of the inferior colliculus. In: The inferior colliculus (Winer JA, Schreiner CE, eds), pp 69-114. New York: Springer.

Oliver DL, Cant NB (2018) Overview of auditory projection pathways and intrinsic microcircuits. In: The mammalian auditory pathways synaptic organization and microcircuits (Oliver DL, Cant NB, Fay RR, Popper AN, eds), pp 7-39. New York: Springer.

Oliver DL, Winer JA, Beckius GE, Saint Marie RL (1994) Morphology of GABAergic neurons in the inferior colliculus of the cat. J Comp Neurol 340:27-42. CrossRef Medline

Olthof-Bakker BMJ, Lyzwa D, Gartside SE, Rees A (2017) Evidence that the tinnitus-inducing agent salicylate has a direct effect on neural activity in the inferior colliculus. Assoc. Res. Otolaryngol. Abs: p509.

Orton LD, Rees A (2014) Intercollicular commissural connections refine 
the representation of sound frequency and level in the auditory midbrain. eLife 3:e03764. CrossRef Medline

Palmer AR, Shackleton TM, Sumner CJ, Zobay O, Rees A (2013) Classification of frequency response areas in the inferior colliculus reveals continua not discrete classes. J Physiol 591:4003-4025. CrossRef Medline

Patel CR, Zhang H (2014) Local application of sodium salicylate enhances auditory responses in the rat's dorsal cortex of the inferior colliculus. Front Neurol 5:235. CrossRef Medline

Rees A (1990) A closed-field sound-system for auditory neurophysiology. J Physiol 430:P6.

Russwurm M, Wittau N, Koesling D (2001) Guanylyl cyclase/PSD-95 interaction: targeting of the nitric oxide-sensitive alpha2betal guanylyl cyclase to synaptic membranes. J Biol Chem 276:44647-44652. CrossRef Medline

Serulle Y, Zhang S, Ninan I, Puzzo D, McCarthy M, Khatri L, Arancio O, Ziff EB (2007) A GluR1-cGKII interaction regulates AMPA receptor trafficking. Neuron 56:670-688. CrossRef Medline

Sheng M, Hoogenraad CC (2007) The postsynaptic architecture of excitatory synapses: a more quantitative view. Annu Rev Biochem 76:823-847. CrossRef Medline

Shibuki K, Okada D (1991) Endogenous nitric oxide release required for long-term synaptic depression in the cerebellum. Nature 349:326-328. CrossRef Medline

Slee SJ, David SV (2015) Rapid task-related plasticity of spectrotemporal receptive fields in the auditory midbrain. J Neurosci 35:13090-13102. CrossRef Medline

Song RS, Tolentino R, Sobie EA, Neves-Zaph SR (2016) Cross-regulation of phosphodiesterase 1 and phosphodiesterase 2 activities controls dopaminemediated striatal $\alpha$-amino-3-hydroxy-5-methyl-4-isoxazolepropionic acid (AMPA) receptor trafficking. J Biol Chem 291:23257-23267. CrossRef Medline

Steinert JR, Kopp-Scheinpflug C, Baker C, Challiss RA, Mistry R, Haustein MD, Griffin SJ, Tong HX, Graham BP, Forsythe ID (2008) Nitric oxide is a volume transmitter regulating postsynaptic excitability at a glutamatergic synapse. Neuron 60:642-656. CrossRef Medline
Steinert JR, Robinson SW, Tong H, Haustein MD, Kopp-Scheinpflug C, Forsythe ID (2011) Nitric oxide is an activity-dependent regulator of target neuron intrinsic excitability. Neuron 71:291-305. CrossRef Medline

Suga N, Ma X (2003) Multiparametric corticofugal modulation and plasticity in the auditory system. Nat Rev Neurosci 4:783-794. CrossRef Medline

Szabadits E, Cserép C, Ludányi A, Katona I, Gracia-Llanes J, Freund TF, Nyíri G (2007) Hippocampal gabaergic synapses possess the molecular machinery for retrograde nitric oxide signaling. J Neurosci 27:8101-8111. CrossRef Medline

Valtschanoff JG, Weinberg RJ (2001) Laminar organization of the NMDA receptor complex within the postsynaptic density. J Neurosci 21:12111217. CrossRef Medline

Watson RE Jr, Wiegand SJ, Clough RW, Hoffman GE (1986) Use of cryoprotectant to maintain long-term peptide immunoreactivity and tissue morphology. Peptides 7:155-159. Medline

Yan W, Suga N (1998) Corticofugal modulation of the midbrain frequency map in the bat auditory system. Nat Neurosci 1:54-58. CrossRef Medline

Yassin L, Radtke-Schuller S, Asraf H, Grothe B, Hershfinkel M, Forsythe ID, Kopp-Scheinpflug C (2014) Nitric oxide signaling modulates synaptic inhibition in the superior paraolivary nucleus (SPN) via cGMPdependent suppression of KCC2. Front Neural Circuits 8:65. CrossRef Medline

Young ED, Robert JM, Shofner WP (1988) Regularity and latency of units in ventral cochlear nucleus - implications for unit classification and generation of response properties. J Neurophysiol 60:1-29. CrossRef Medline

Zhang H, Kelly JB (2001) AMPA and NMDA receptors regulate responses of neurons in the rat's inferior colliculus. J Neurophysiol 86:871-880. CrossRef Medline

Zheng Y, Seung Lee H, Smith PF, Darlington CL (2006) Neuronal nitric oxide synthase expression in the cochlear nucleus in a salicylate model of tinnitus. Brain Res 1123:201-206. CrossRef Medline 